\title{
Universitas Psychologica: un camino hacia la internacionalización
}

\section{Universitas Psychologica: a Pathway towards Internationalization}

Recibido: 08 de febrero de 2016| Aceptado: 01 de marzo de 2016

\author{
EdUARDO AgUAdO-LÓPEZ ** \\ ARIANNA BECERRIL-GARCÍA ${ }^{* * *}$ \\ Universidad Autónoma del Estado de México, Toluca, México \\ María ConstanZa Aguilar Bustamante ${ }^{* * * * *}$ \\ Universidad de Santo Tomás de Aquino, Bogotá, Colombia
}

doi: 10.11144/Javeriana.upsy15-2.upci

Para citar este artículo: Aguado-López, E., BecerrilGarcía, A., \& Aguilar, M. C. (2016). Universitas Psychologica: un camino hacia la internacionalización. Universitas Psychologica, 15(2), 321-338. http://dx.doi.org/10.11144/Javeriana.upsy15-2.upci

* Artículo de investigación científica y tecnológica.

** Profesor-Investigador FCPyS-UAEM. Edificio Redalyc, Cerro de Coatepec s/n, Ciudad Universitaria. C.P. 50100. Toluca, México. Correo electrónico: eal123@gmail.com

${ }^{* * * *}$ Profesora-Investigadora FCPyS-UAEM. Edificio Redalyc. Cerro de Coatepec s/n, Ciudad Universitaria. C.P. 50100. Toluca, México. Correo electrónico: arianna.becerril@gmail.com

${ }^{* * * * * *}$ Universidad Santo Tomás, Colombia. Correo electrónico: Mariaaguilar@usantotomas.edu.co

\section{RESUMEN}

La internacionalización se ha convertido en una meta generalizada para todos los actores involucrados a la ciencia, quienes buscan una visibilidad fuera de las fronteras nacionales a partir de una lógica exógena en el proceso de construcción del conocimiento. Observando esto, se analiza la hoja de ruta de Universitas Psychologica en su camino a la internacionalización. Se concluye que dicha publicación es un referente en el debate científico de la psicología, dado el peso predominante de la producción externa, impulsada principalmente por la colaboración de autores extranjeros. Esta apertura al exterior se replica en la producción interna y en el uso de la revista, cuyas descargas se realizan principalmente fuera del país editor. Para el análisis, se consideran los casi 1000 artículos de la revista, integrados a redalyc.org del periodo 2002-2015, utilizando de los indicadores de producción, colaboración y uso que dicha base de datos ofrece.

Palabras clave

internacionalización; proceso de construcción del conocimiento; Universitas

Psychologica; redalyc.org

\section{A B S T R A C T}

Internationalization has become a widely accepted goal among all stakeholders in science, who seek visibility across national borders from an exogenous logic in the process of knowledge construction. With this in mind, the road map of Universitas Psychologica - on its way to internationalization- is analyzed. It is concluded that such publication is a reference in the scientific debate of Psychology, given the predominant weight of foreign production, driven mainly by foreign author collaboration; this openness is replicated in domestic production and in the journal usage, whose downloads take place primarily outside the journal's country. For the analysis, it is considered almost a thousand articles of this journal integrated in redalyc.org published in the period from 2002 to 2015 ; by using the indicators provided by this database related to production, collaboration and usage.

Keywords

internationalization; knowledge construction process; Universitas Psychologica; redalyc.org 


\section{Introducción}

El concepto "internacionalización” forma parte de la noción que, de manera general, se tiene actualmente de "productividad" y "competitividad" científicas (Gallegos, Berra, Benito, \& López-López, 2014; Zych \& Buela-Casal, 2007). Constituye uno de los aspectos que más se prioriza en los actuales sistemas de evaluación del desempeño científico en las universidades y consejos de ciencia y tecnología, y uno de los objetivos que se busca desde los sistemas de información y legitimación de la ciencia escrita, como los grandes repositorios y bases de datos.

Entre los objetivos de todos los actores involucrados en la concepción, producción, distribución y comunicación del conocimiento científico (LópezLópez, 2014) está el ser tomados en cuenta, tener impacto, visibilidad y que todo ello suceda en una comunidad heterogénea, dentro y fuera de las fronteras nacionales. Se trata de una característica implícita a la ciencia escrita del siglo XXI en todas las áreas de conocimiento y regiones geográficas, y de una dinámica de la que todo actor, dígase universidad, autor, revista, país o región, busca participar.

Pese a que todos los actores involucrados en el quehacer científico observan en la internacionalización una tarea necesaria y provechosa, no convienen en una única manera de concebirla. La multidimensionalidad con que se piensa la internacionalización se observa en las diversas formas en que se busca y se mide, tales como: la participación en redes de colaboración internacionales, principalmente con países occidentales "desarrollados"; índices de citas que cuenten con referentes extranjeros; consulta de la producción fuera de las fronteras nacionales; publicación en revistas de "corriente principal"; indización de revistas por grandes sistemas de información; adopción de agendas de investigación sugeridas desde los "circuitos científicos principales"; movilidad en programas de grado y posgrado; acuerdos interinstitucionales de cooperación y factor de impacto (Garfield, 2006; López, 2013; Sá-Carvalho, Travassos, \& MedinaCoeli, 2014; Sánchez-Pereyra, Carrillo-Romero, \& Garrido-Villegas, 2015; Santin, De Souza-Vanz, \& Caregnato, 2015; UNESCO, 2010).
En el caso latinoamericano, la internacionalización es una noción que ha acompañado a la ciencia y la investigación desde sus orígenes en la región (Kreimer, 2011), dado que a través de esta se busca formar parte de la narrativa científica global, aspecto que se encuentra en construcción, ya que si bien en la actualidad la participación del Sur Global se encuentra transformando el mapa de producción científica (Banerjee, Babini, \& Aguado-López, 2015), con la existencia de una ciencia de corriente principal se asume también la existencia de una ciencia de segundo orden, es decir, la ciencia continúa desarrollándose en una estructura científica asimétrica y desigual (Vessuri, 2013a).

En el camino permanente hacia la internacionalización, la psicología se destaca en las ciencias sociales por constituir una comunidad altamente productiva desde esquemas inclusivos y diversos. Específicamente, se destaca el papel que Universitas Psychologica (UP), de la Pontificia Universidad Javeriana, ha desempeñado desde 2002, año de su fundación. Dicho proyecto editorial muestra un interés por contribuir a la psicología desde un esquema plural. Observando lo anterior, es que se efectúa un análisis de la labor que dicha publicación ha realizado en términos de internacionalización de la psicología, recurriendo a la evidencia que redalyc.org ofrece desde el Sistema de Información Científica, a partir de los artículos que la revista ha publicado de 2002 a 2015 y atendiendo a sus indicadores de producción, colaboración y uso.

\section{Metodología y universo de estudio}

El universo fuente contextual lo constituyen las 82 revistas del área de psicología, indizadas y normalizadas de redalyc.org, las cuales reúnen 20587 artículos de 2005 a 2014. Específicamente, se analizan los cerca de mil artículos (895) que UP ha publicado y que se desprenden de 45 fascículos integrados en dicha base de datos.

Con la finalidad de poder hacer un recorrido por la trayectoria de la revista y mostrar en figuras y tablas su hoja de ruta, se decidió ampliar el 
período de estudio abarcando el lapso 2002-2015 y el análisis se llevó a cabo sobre los artículos científicos, excluyendo los 37 editoriales, 13 reseñas y 14 textos académicos clasificados en varios, para abarcar únicamente escritos que han pasado por un sistema de revisión por pares, y poder cumplir el objetivo de identificar el papel que ha tenido la revista al interior de la comunidad científica internacional de psicología.

Para tal enmienda, se realizaron análisis cuantitativos, cualitativos y geofiguras (figuras 1 - 10) con el fin de observar la composición y el comportamiento de los actores que han participado en la revista. En tales procesos analíticos se encuentra, principalmente, el análisis de la producción externa a partir de las tres variables que la componen (A. autores extranjeros que han publicado individualmente, B. autores extranjeros que han colaborado con otros autores extranjeros y C. autores extranjeros que han colaborado con autores adscritos a instituciones colombianas), tanto de la revista en cuestión como del total de revistas del área, con miras a contextualizar su comportamiento y composición. Además del análisis del comportamiento de la producción nacional (compuesta por la producción institucional -artículos de autores adscritos a la institución editora- y la producción nacional no institucional -artículos de autores adscritos a instituciones colombianas-) y el uso de los artículos en 2013 y 2014 (los años que redalyc.org dispone para observar la descarga de los artículos de las distintas revistas de su acervo).

\section{TABLA 1}

Universo fuente y universo de estudio

\begin{tabular}{|c|c|c|}
\hline & Psicología & $\begin{array}{c}\text { Universitas } \\
\text { Psychologica }\end{array}$ \\
\hline Artículos & 20,587 & 895 \\
\hline Artículos colaborativos & 15,569 & 696 \\
\hline Artículos de una autoría & 5,018 & 199 \\
\hline Editoriales & 443 & 37 \\
\hline Reseñas & 804 & 13 \\
\hline Otros textos & 445 & 14 \\
\hline Instituciones & 3,023 & 346 \\
\hline Países & 90 & 36 \\
\hline Formas de autor & 55,005 & 2,259 \\
\hline
\end{tabular}

Fuente: redalyc.org, UAEM. 


\section{Resultados}

\section{Universitas Psychologica en el} contexto iberoamericano

Las revistas del área se han entendido como órganos de comunicación global, es decir, como medios que captan la producción más relevante de los investigadores internacionales de la disciplina, pero con énfasis en la región iberoamericana por la similitud de sus condiciones socioeconómicas. El objetivo último de las revistas ha sido ser un referente en el debate disciplinario.

La condición global de una revista no solo se define por las problemáticas que discurren en sus páginas, que pueden ser globales, regionales o locales, sino también y sobre todo por las características de los colaboradores que nutren sus páginas, sean ellos internacionales, nacionales o institucionales. Una revista puede tener una definición temática clara, mayor o menormente acotada, no obstante, si lo que se pretende es ser punto de referencia en la narrativa global del conocimiento, pareciera natural que se busque congregar a los colegas de diferentes partes de la región y el mundo para participar en la construcción colectiva del conocimiento. Esta es la función principal de una revista.

En este sentido, resulta evidente que mientras mayor sea la proporción de autores extranjeros y haya una mayor diversidad de países, la revista está mostrando la forma en que es reconocida y elegida por los colegas de otras naciones para publicar sus productos de investigación. De esta forma, la producción externa constituye el indicador de reconocimiento externo, el cual puede ser identificado por la proporción de artículos que cuentan con la participación de un extranjero, al menos. En el caso de las 82 revistas en cuestión, la producción externa se mantuvo al alza en el período referido: pasó de representar el $24 \%$ de la producción general en 2005, al 37 \% en 2014.

Una característica sobresaliente de las revistas del área es que han dejado de ser endógenas y tienen una clara presencia nacional. En 2014, solo una revista mostraba más del 50 \% de producción institucional y seis revistas presentaban entre el 20 y el $50 \%$. En resumen, prácticamente la totalidad de las revistas contaban con un nivel de endogeneidad institucional menor o igual al $20 \%$. Por otro lado, más de una cuarta parte de las revistas (24) mostraron en 2014 más del $75 \%$ de producción nacional no institucional y también 24 revistas presentaron entre el 50 y el $75 \%$ de la producción nacional. En resumen, en el $58 \%$ de las revistas, la producción nacional no institucional representó más del 50 \% en 2014 (Figura 1).

Una tercera parte de las revistas (26) tuvieron una clara presencia internacional, al presentar más del $50 \%$ de producción externa en 2014. En este grupo se identifican dos subgrupos: por un lado, se ubican las revistas internacionales en consolidación, que son las que presentan entre el 50 y el $75 \%$ de producción externa (17 revistas) y, por otra parte, se ubican las revistas internacionales consolidadas, que presentan más del $75 \%$ de producción externa: Revista Argentina de Clínica Psicológica, Argentina (100\%); Revista de Psicología, Perú (100\%); Universitas Psychologica, Colombia (92 \%); Revista Latinoamericana de Psicología, Colombia (90.9\%); Revista Mexicana de Psicología, México (85\%); Avances en Psicología Latinoamericana, Colombia (79.4\%); Acta Colombiana de Psicología, Colombia (78.6\%); Interamerican Journal of Psychology, Brasil (78.1 \%) y Suma Psicológica, Colombia (75\%).

Sobresale que de las nueve revistas consolidadas internacionalmente, más de la mitad sean colombianas: cinco revistas. Asimismo, de un análisis por país, se identificaría que las revistas brasileñas muestran una clara presencia nacional, ya que superan el $80 \%$ de la producción interna en tres de cada cuatro revistas, solo cuatro registran una producción externa entre el 27 y el $46 \%$ y una revista (Interamerican Journal of Psychology) tiene $78 \%$ de producción externa. Conviene mencionar que en el período 2005 2014 estaban indizadas 82 revistas iberoamericanas de psicología en redalyc.org, de las cuales tres no presentaron producción en el año 2014 (Revista Portuguesa de Psicossomática (Portugal), Psychê (Brasil) e Interações (Brasil). De tal for- 

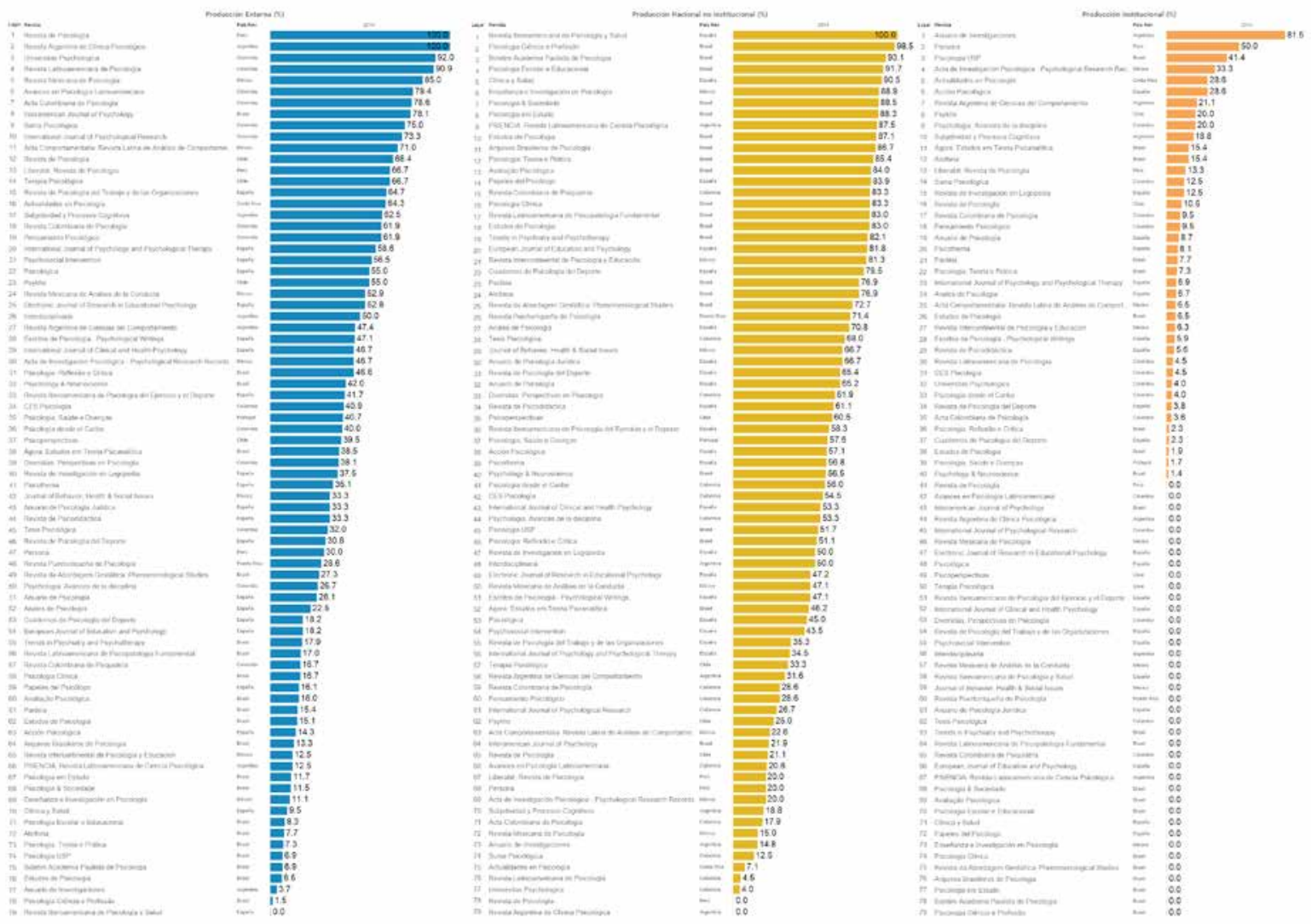

Figura 1. Producción externa, producción institucional y producción nacional no institucional en las revistas de psicología de redalyc.org, 2014.

Fuente: redalyc.org, UAEM.

ma, las 79 revistas restantes, que son las que se muestran en la Figura 1, están distribuidas de la siguiente forma: Brasil y España contaban con 21 cada uno, seguidos de Colombia con 14, México 7, Argentina 6, Chile 4, Perú 3; Portugal, Puerto Rico y Costa Rica con 1 cada uno.

\section{Contribución y esfuerzo editorial}

En el análisis, las revistas se identifican como entidades similares y si bien se distinguen por sus características (composición de la producción, periodicidad, citas recibidas, factor de impacto, tasas de colaboración, etc.), pocas veces se analizan -particularmente se diferencian- a partir de la forma cuantitativa en que contribuyen al debate científico, lo que significa realizar un esfuerzo editorial específico día a día.
No representa el mismo esfuerzo editorial un anuario que publica 10 artículos - suponiendo una tasa de rechazo del $50 \%$-, que tuvo que valorar 15 artículos y contar con cerca de 30 evaluadores, que una revista que publica 100 artículos al año -suponiendo una tasa de rechazo del $50 \%$-y que tuvo que contar con cerca de 300 evaluadores para realizar el proceso de revisión por pares. Resulta evidente que no significa el mismo esfuerzo editorial, difícilmente puede hablarse del equipo editorial que debe acompañar a una revista sin tomar en cuenta el Índice de Contribución y Esfuerzo Editorial (ICyEE).

Se propone para su medición una razón: Cantidad de artículos al año/Promedio de artículos al año de la disciplina. Si el resultado fuera 1, indicaría que la revista mantiene una Contribución y Esfuerzo Editorial igual que el promedio de las revistas del área. Si resultara 2, tendría un ICyEE del doble. Si 
fuera 0.5 tendría un ICyEE de la mitad que el promedio de las revistas.

Como puede observarse en la Tabla 2, en el área de psicología la variación es muy grande y se incrementa el ICyEE al pasar de 21.6 en 2005 a 31.8 en 2014. En este sentido, pareciera que no basta mantener una revista, sino que parte de las buenas prácticas editoriales de las revistas que están jugando un papel cada día más importante es incrementar su ICyEE, ya sea mediante el aumento de la periodicidad o mediante la integración de números que ya no están limitados por la dimensión del papel y del volumen de una revista impresa, cuyo número de artículos oscilaba entre 8 y 15 en las ciencias sociales.

En la década estudiada, UP ha mantenido un ICyEE superior al promedio y la distancia ha crecido en la medida que avanza el tiempo. Así, en 2005 su ICyEE fue de 1.45, en 2010 asciende a 2.1 y en 2014 a 4.7.

\section{Producción y diversificación}

UP puede considerarse una revista consolidada de corte internacional, dado que de la producción que ha registrado en 14 años en redalyc.org (20022015), el $74 \%$ corresponde a la producción externa (cabe mencionar de nuevo que $92 \%$ de producción externa que se indicó en la Figura 1 corresponde al período 2014), es decir, artículos donde han participado autores extranjeros. Sin embargo, el análisis del comportamiento longitudinal de la producción externa y la nacional permite identificar dos periodos en el enfoque de la revista en términos de apertura (Figura 2). En primer lugar, el periodo de 2002 a 2006: cinco años que constituyen una fase de reconocimiento y legitimación del proyecto ante la institución editora y la comunidad científica nacional que se identifica por el mayor peso de la producción nacional, dada la composición nacional-institucional de la revista. En segundo

TABLA 2

Índice de Contribución y Esfuerzo Editorial de Universitas Psychologica en las revistas de psicología en redalyc.org

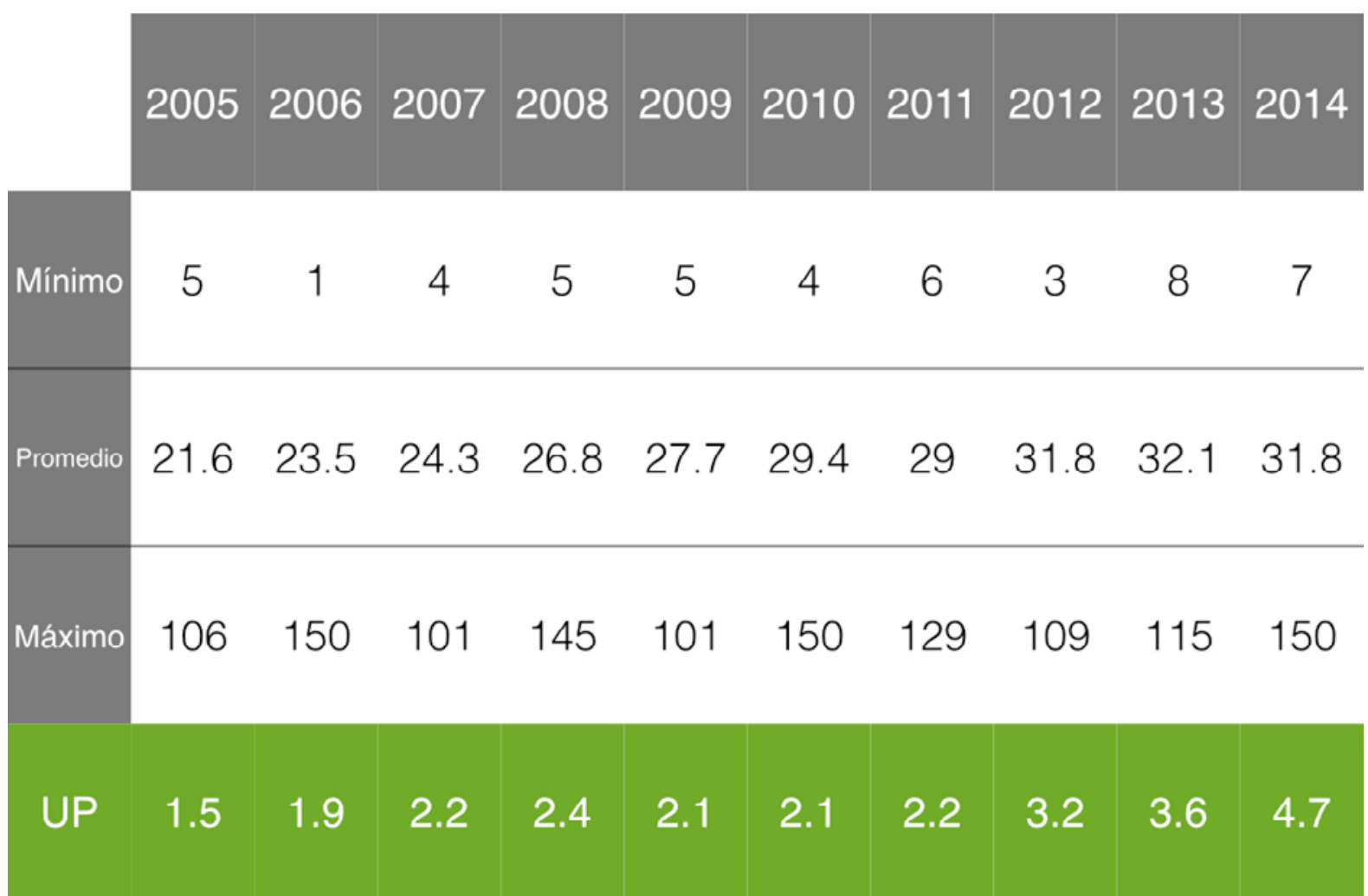

Fuente: redalyc.org, UAEM. 
término, a partir de 2007 tuvo lugar una apuesta hacia la internacionalización; es entonces cuando la producción externa comenzó a tener una presencia predominante y en permanente crecimiento. El viraje a la internacionalización de UP se observa además en los ritmos de crecimiento para ambos tipos de producción: la nacional muestra una Tasa de Crecimiento Media Acumulada (TCMA) del 25 $\%$, mientras la externa es del $39 \%$. Dichos momentos se ven con claridad en la Figura 1, en la que se aprecia que la producción nacional en los últimos tres años osciló entre 7 y $10.8 \%$.

De tal forma, se observa un esfuerzo editorial para hacer de la revista un referente internacional de debate, lo que se refleja en un peso creciente y predominante de la producción externa en los últimos años. La comunidad científica que contribuye a la psicología a partir de la revista está integrada principalmente por autores extranjeros, no obstante, su participación ha sido de tres formas distintas: individualmente (caso A), colaborando con otros autores extranjeros (caso B) y colaborando con autores adscritos a instituciones colombianas (caso C).

De las tres variables que componen la producción externa, el caso de los autores extranjeros que han participado individualmente es el que ocupa la segunda posición en recurrencias. Como se observa en la Figura 3, se tienen 123 incidencias y resalta que los autores que más han participado de esta forma provienen principalmente de Chile (con 25 casos), España (20), Brasil (18) y Argentina (18); aunado a ello, se tienen otros 42 casos, provenientes de 17 países más.

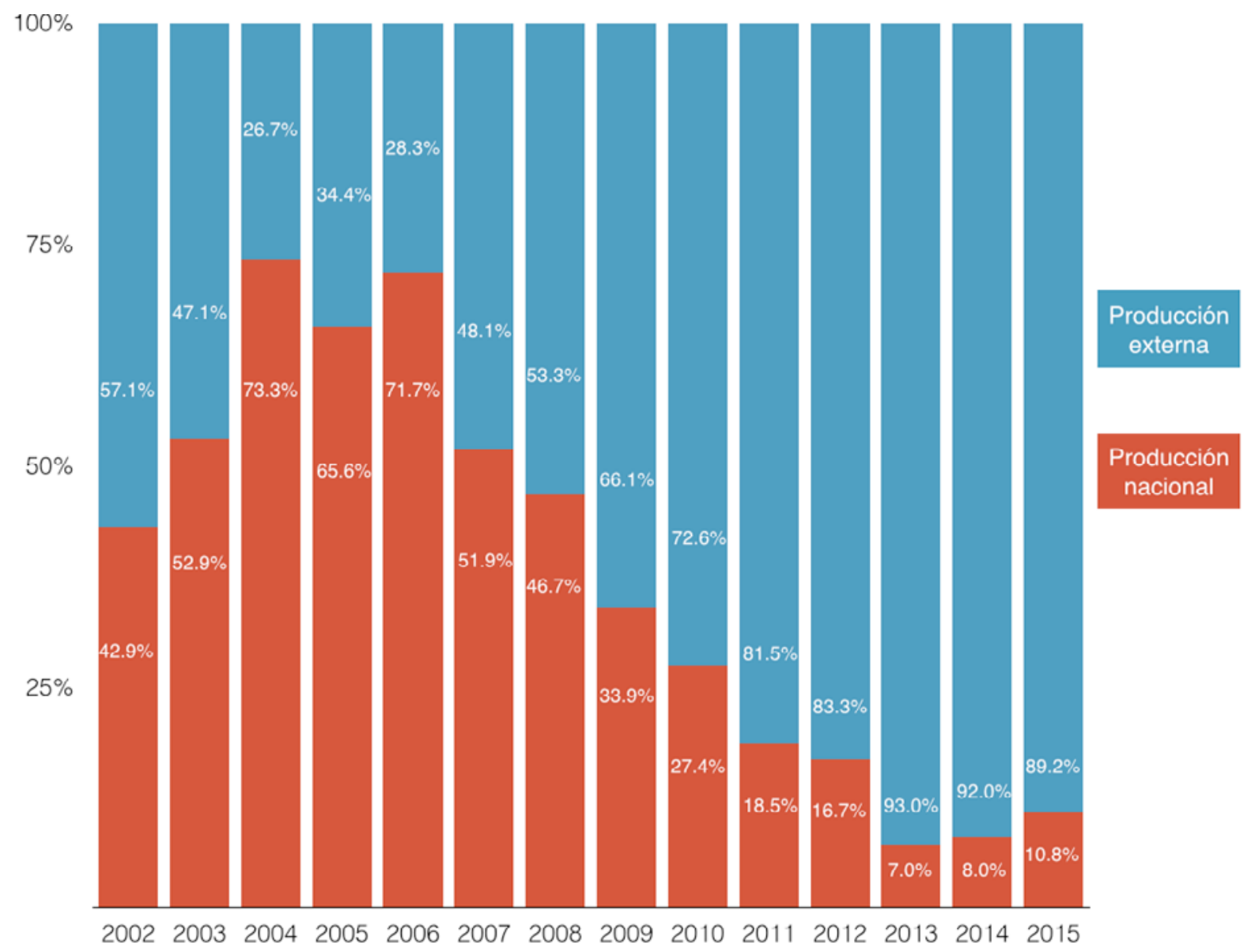

Figura 2. Distribución de la producción nacional y la producción externa en Universitas Psychologica, 2002-2015.

Fuente: redalyc.org, UAEM.

| Universitas Psychologica | V.15 | No.2 | Abril-junio | 2016 


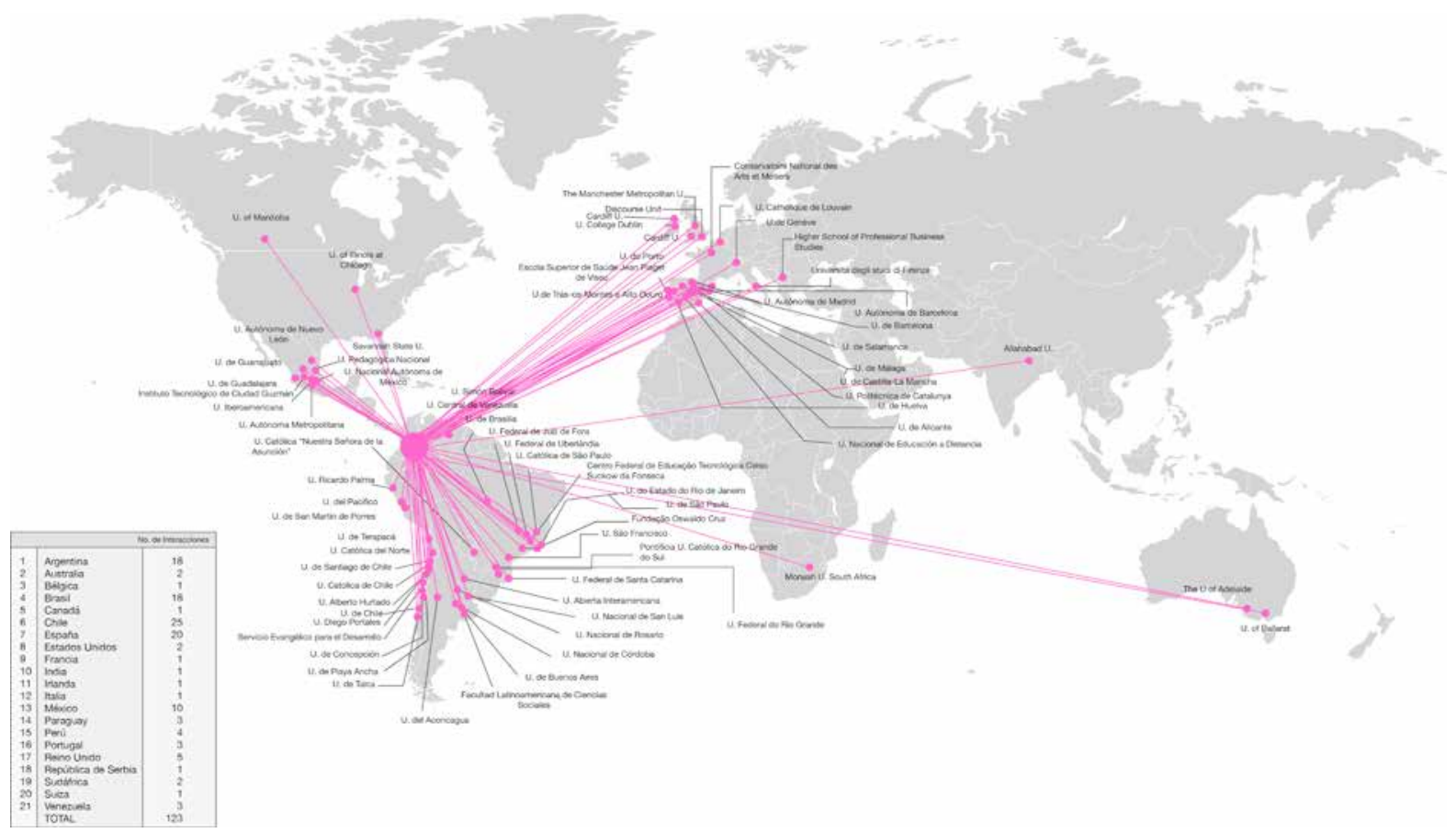

Figura 3. Procedencia geográfica e institucional de los autores extranjeros que participan individualmente en Universitas Psychologica, 2002-2015.

Fuente: redalyc.org, UAEM.

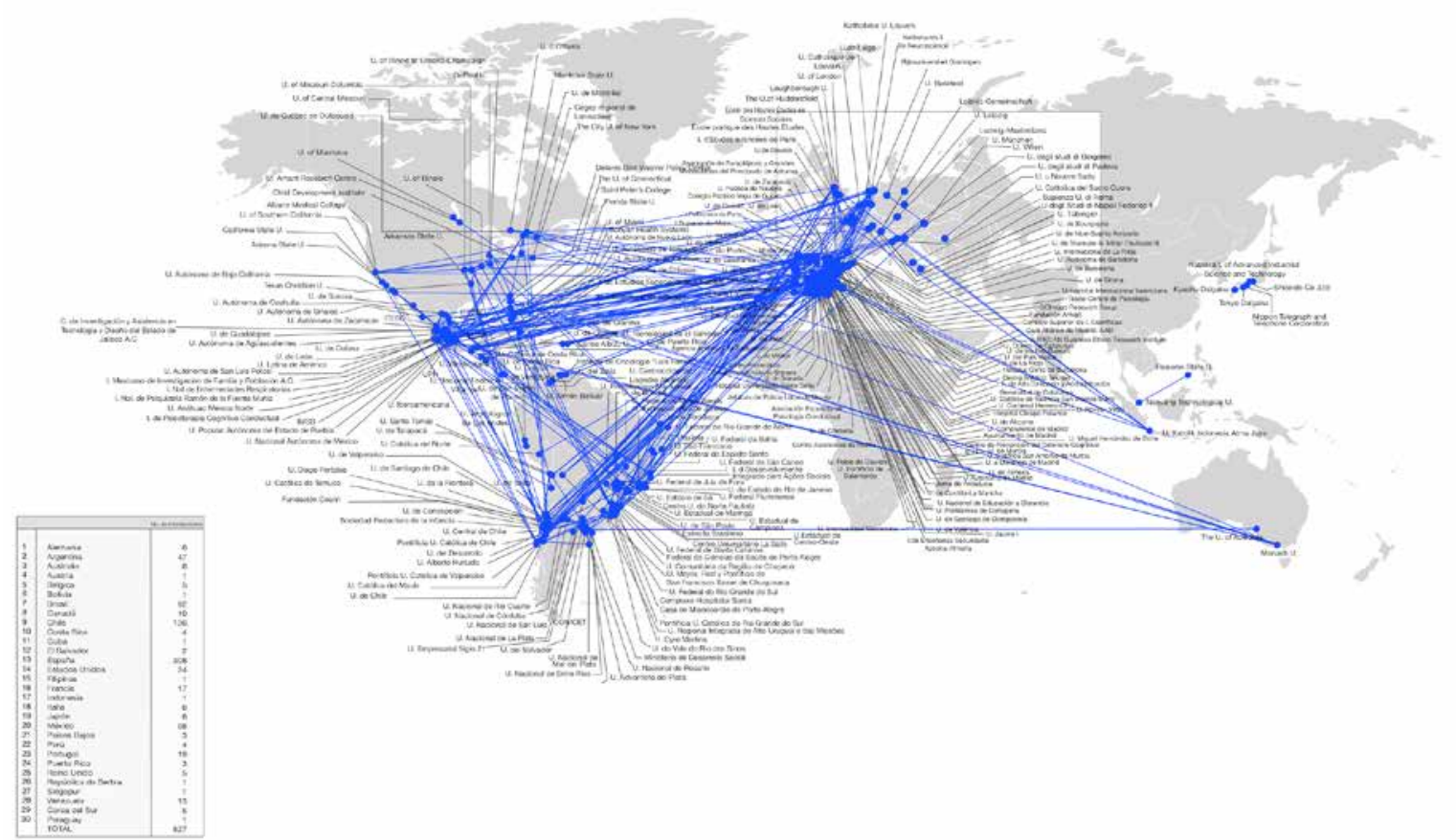

Figura 4. Procedencia geográfica e institucional de los autores extranjeros en coautoría con otros autores extranjeros en Universitas Psychologica, 2002-2015.

Fuente: redalyc.org, UAEM. 
Por su parte, el caso de los autores extranjeros que han participado en colaboración con otros autores extranjeros es el más recurrido, con 827 interacciones, y el que involucra a más países, 31 exactamente. En la Figura 4, se muestra la procedencia geográfica e institucional de los autores que han participado de tal forma en UP, destacando España con 308 interacciones, Chile con 136, México con 98 y Brasil con 92. La representación de tal forma de participar en la revista conforma un mapa denso que refleja que esta es reconocida por la comunidad internacional como un vehículo para comunicar contribuciones a la psicología, principalmente desde un esquema colaborativo entre autores extranjeros.

Finalmente, el caso de los autores extranjeros que colaboran con autores adscritos a instituciones colombianas presenta 113 interacciones con participación de 15 países (Figura 5), siendo el caso menos recurrido. Resalta el caso de España como el país con el que los autores adscritos a Colombia tienen redes de colaboración más sólidas.

El peso y el crecimiento de la producción externa en UP solo adquiere sentido, si se analizan con detenimiento las variables que componen este tipo de producción y se observa a partir de cuál de estas participa la comunidad internacional. Se tiene que la colaboración entre autores extranjeros es el componente con mayor número de interacciones (827) y el que involucra más países (31); en segundo lugar, se encuentran los autores que han publicado individualmente, con 123 interacciones y 21 países; por último, se tiene la colaboración de autores extranjeros con autores adscritos a instituciones colombianas, con 113 interacciones e involucrando 15 países.

Se ha observado la creciente adhesión de los actores que participan en UP, provenientes principalmente del extranjero. No obstante, conviene tener en cuenta también la diversificación de estos actores, haciéndolo a través del análisis de la producción por países, que desagregada de esta forma tiene como resultado un total de 1026 artículos. En la Tabla 3, se observa, por ejemplo, que en 2002 se registraron cinco participaciones de autores de dos países (Colombia y España). En 2003, se incrementó la participación de los autores a 11 y también los países, que suman 4, dado que se agregó Chile

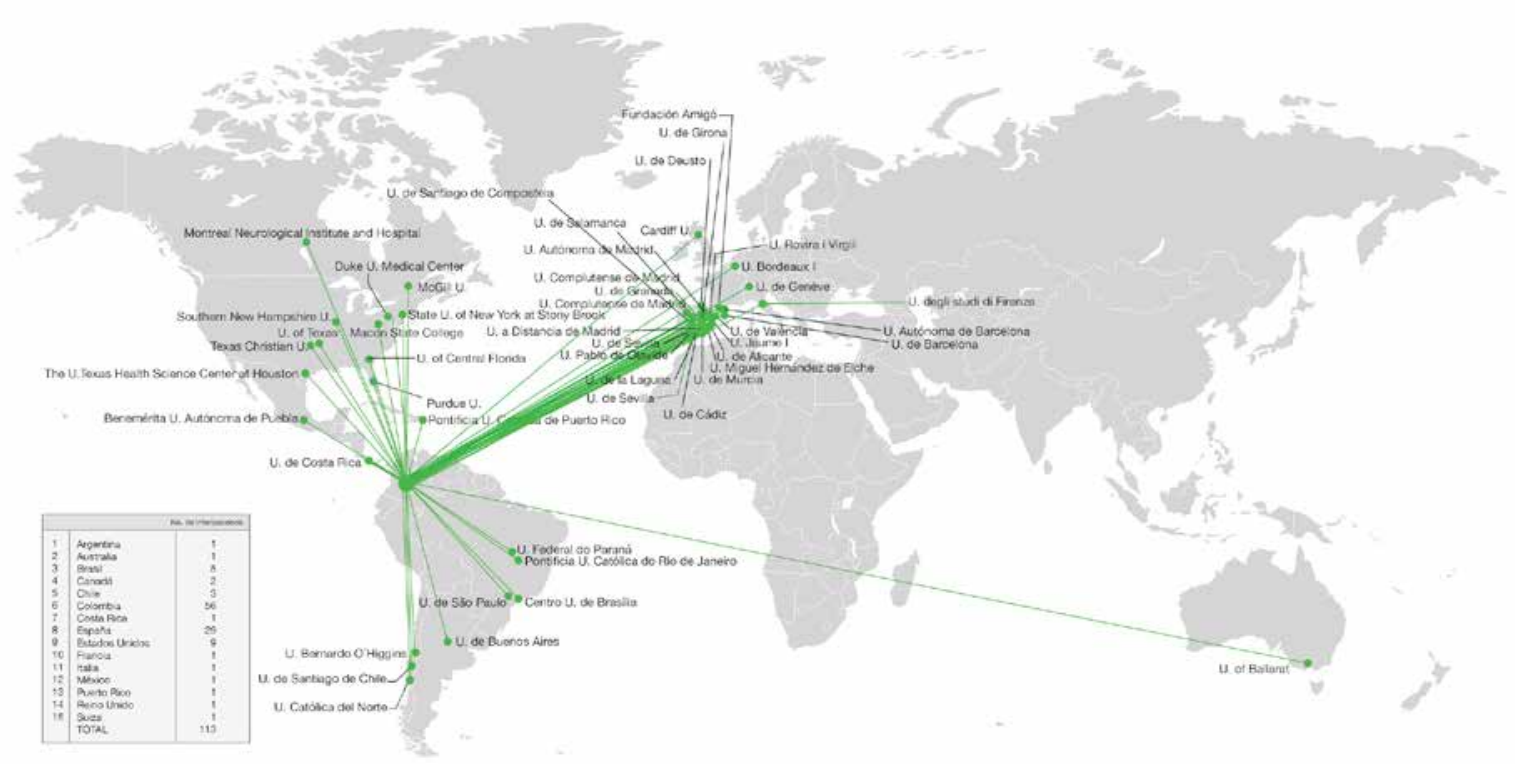

Figura 5. Procedencia geográfica e institucional de los autores extranjeros en coautoría con autores adscritos a instituciones colombianas, en Universitas Psychologica, 2002-2015.

Fuente: redalyc.org, UAEM. 
y México. Tal lógica se replica en lo general hasta que, por ejemplo, en 2013 se observan 140 participaciones de 25 países; en 2014, 190 participaciones de 21 países y en 2015, 132 participaciones de 19 países. Esto es, sin duda, un esfuerzo editorial de envergadura, posicionamiento y reconocimiento para la psicología regional.

A su vez, en la Tabla 3, se observa la cantidad de participaciones por país y por año, al tiempo que el degradado de colores hace referencia a la presencia anual de los países en la revista. Se tiene por ejemplo la presencia de Colombia en los 14 años del período de estudio y registrando $26.1 \%$ de los artículos; en segundo lugar está España, que participa en 12 años (excepto 2004 y 2006) y representa $24.1 \%$ de la producción; en tercer lugar, se encuentra Chile, que ha participado 11 años, exceptuando 2002, 2004 y 2006 y representa $12.1 \%$; mientras que en cuarto lugar se encuentra Brasil, que participa 10 años, dos años menos que México, pero tiene más artículos que este país: representa el 8.6 \% de la producción y México el $7.9 \%$. Así, se llega al caso de Indonesia (2013), Singapur (2013), Austria (2013), Filipinas (2013), Bolivia (2011), Cuba (2010) e India (2013), que solo han participado un año con un artículo.

Lo anterior resulta significativo dado que ilustra la manera en que UP ha apostado por la internacionalización de sus contenidos, construyendo, además, una comunidad que es cada vez más diversa. Esto se percibe, asimismo, en la distribución de la producción en los dos periodos sugeridos anteriormente (2002-2006, 2007-2015), donde en el primero la pro-

TABLA 3

Artículos por año y por país en Universitas Psychologica, 2002-2015

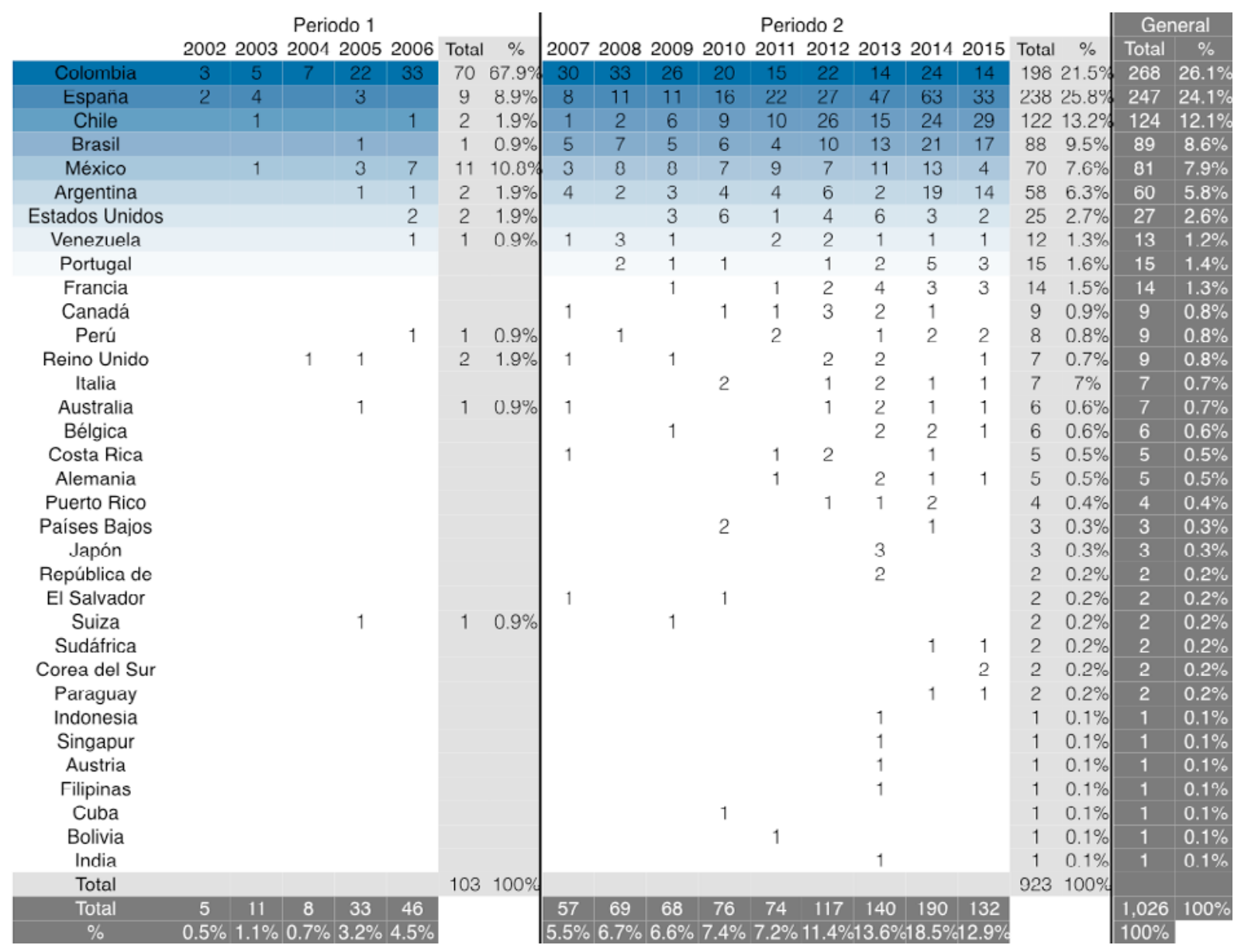

Fuente: redalyc.org, UAEM. 
ducción se concentra en Colombia (67.9\%), México (10.8\%) y España (8.9\%) principalmente; mientras que en el período dos se encuentra distribuida entre más actores y la participación de Colombia se reduce al $21.5 \%$. Se aprecia un esfuerzo editorial en la construcción de una revista inclusiva y plural, no obstante la consecución de esta enmienda debiera traer consigo que la participación de los países que se ubican en el degradado de colores continúe diversificándose entre más y nuevos actores.

Por otra parte, el análisis de la producción nacional arroja que hasta 2005 la producción institucional tuvo un peso predominante, y a partir del año siguiente la no institucional comenzó su tendencia a la alza, como se puede ver en la distribución de ambos tipos de producción en la Figura 6. El buen desempeño de la producción nacional no institucional se refleja de igual forma en los ritmos de crecimiento: mientras esta presenta una TCMA de $52 \%$, la producción institucional registra $23 \%$. Esto permite observar que la apertura que se ha buscado al exterior, se ha replicado al interior de Colombia; se aprecia un esfuerzo editorial por salir de las fronteras institucionales, para darle cabida a las aportaciones de autores adscritos a las demás instituciones nacionales y de tal forma construir una revista heterogénea tanto al interior como al exterior del país.

\section{Colaboración}

El trabajo en conjunto es una estrategia creciente en todas las áreas de conocimiento, ejemplo de ello

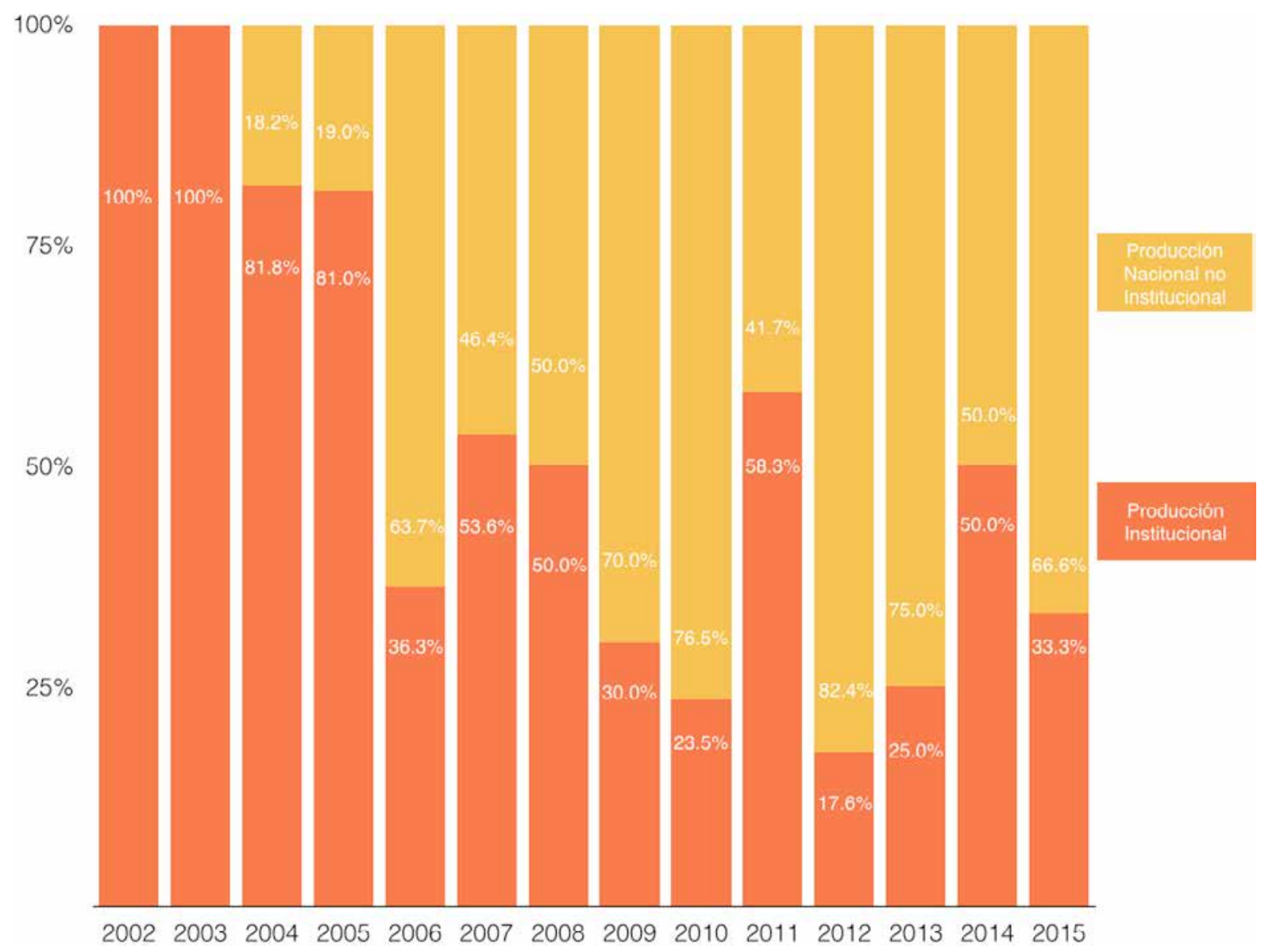

Figura 6. Distribución de la producción institucional y producción nacional no institucional en Universitas Psychologica, 2002-2015.

Fuente: redalyc.org, UAEM. 
es el crecimiento de los artículos colaborativos de las revistas que indiza redalyc.org, donde en 2005 los artículos en coautoría representaron $42.7 \%$ en las ciencias sociales; $11.1 \%$ en las humanidades y $83.5 \%$ en las ciencias naturales y exactas; mientras que en 2014, representaron $62.4 \%, 20.9 \%$ y $91.6 \%$, respectivamente (Aguado-López \& Becerril-García, 2016).

En el caso específico de las ciencias sociales, los artículos colaborativos tuvieron una TCMA de $13.6 \%$ en el mismo periodo, mientras que en el área de psicología tuvieron un ritmo de crecimiento del $11 \%$. UP mantiene una concordancia con lo anterior, ya que la producción en colaboración de la revista muestra una TCMA de $32 \%$, un ritmo de crecimiento superior tanto al de las ciencias sociales como al de la disciplina de psicología. La tendencia a la alza de los artículos colaborativos se aprecia de igual forma observando su comportamiento anual y el de los artículos de una autoría, donde se tiene un crecimiento sostenido de la coautoría desde 2003, como se observa en la Figura 7.

El análisis de los tres tipos de colaboración (Figura 8) lleva a concluir que la colaboración nacional no institucional y la externa han ganado terreno al interior de la revista. Entretanto, se aprecia una contracción de la colaboración institucional (pasa de representar el $80 \%$ de la producción en colaboración en 2002, al $51.8 \%$ en 2015). Ello se explica desde la interacción creciente entre autores de las diversas instituciones colombianas, por una parte, y entre autores de distintos países (entre autores extranjeros y entre autores extranjeros y de instituciones colombianas, como se analizó en las Figuras 4 y 5), por la otra.

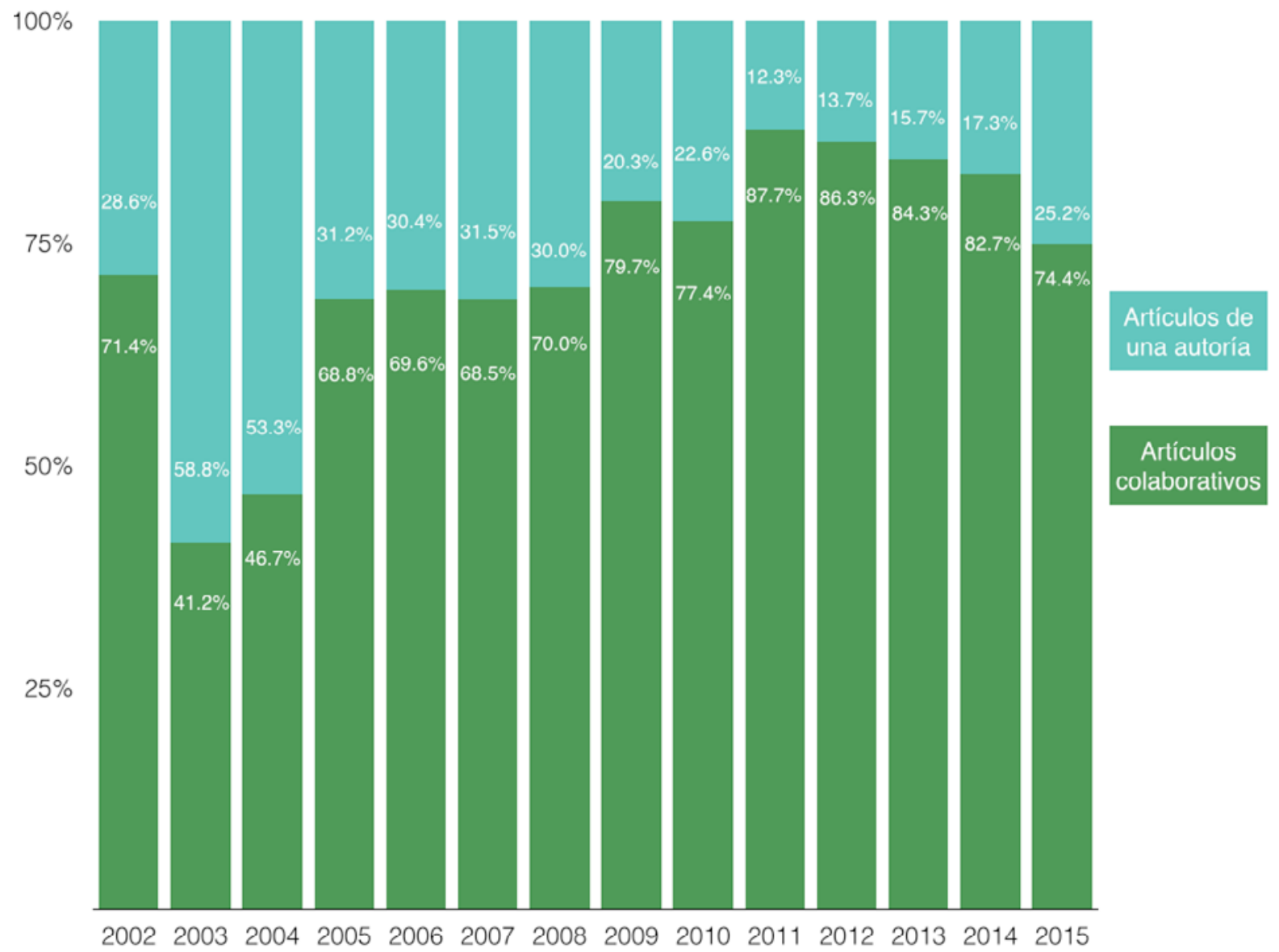

Figura 7. Distribución de los artículos de una autoría y artículos colaborativos en Universitas Psychologica, 2002-2015.

Fuente: redalyc.org, UAEM. 


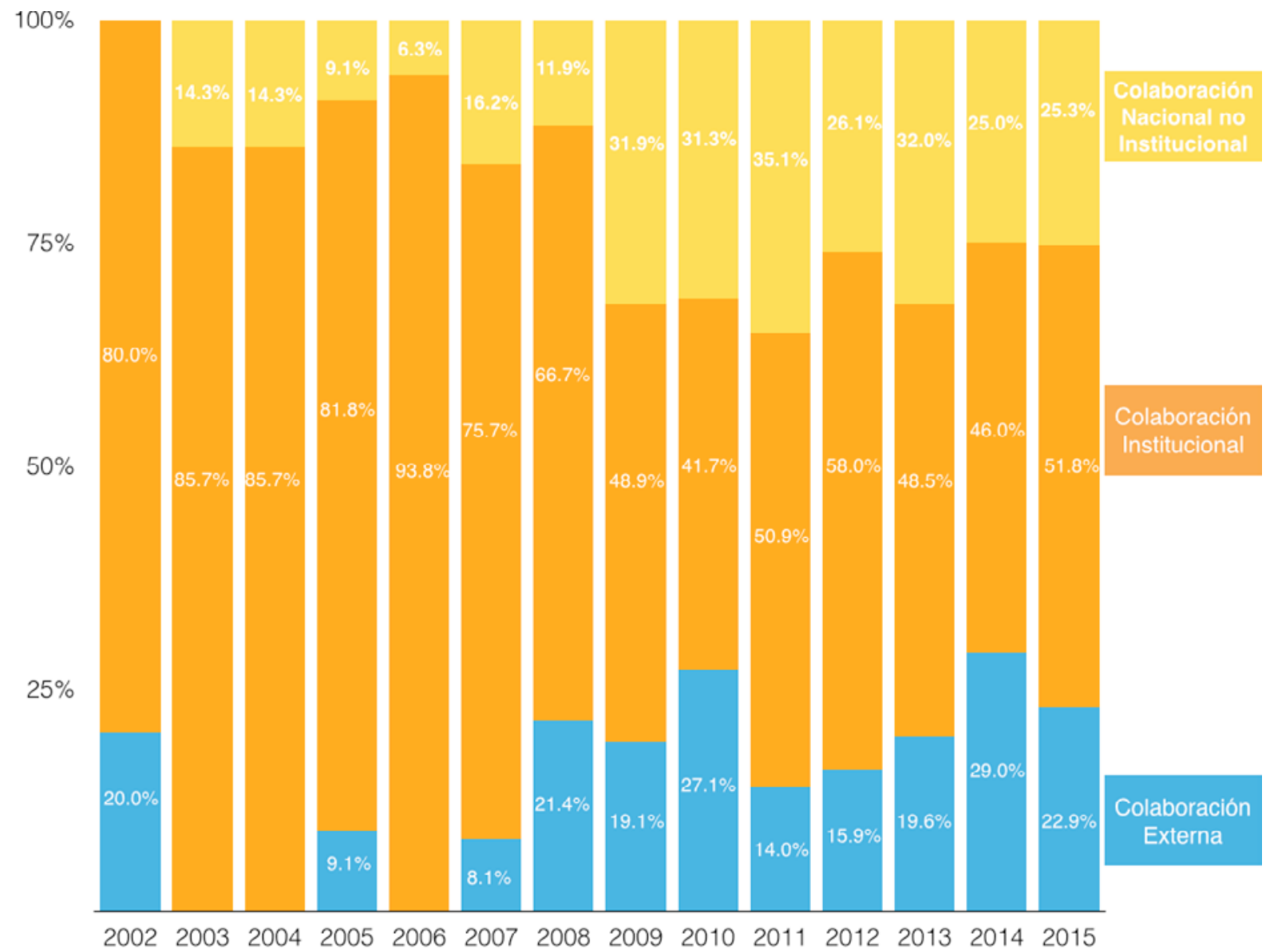

Figura 8. Distribución de los artículos en Colaboración Externa, Institucional y Nacional no Institucional en Universitas Psychologica, 2002-2015.

Fuente: redalyc.org, UAEM.

\section{Uso de Universitas Psychologica}

El análisis de las descargas del acervo de UP permite apreciar que estas han aumentado $58.8 \%$ de enero de 2013 a diciembre de 2014. Además de tener un comportamiento al alza, superan la cantidad promedio de descargas de las revistas de psicología del acervo de Redalyc. Esto en conjunto pone de manifiesto que así como la revista es un referente al interior de la comunidad para publicar, lo es también de consulta y uso.

Asimismo, las descargas provienen principalmente del extranjero $(94.3 \%$ de estas, distribuidas principalmente entre México, Estados Unidos, España y Canadá) y solo 5.7 \% corresponde a descargas en el país editor, como se observa en la Figura 10.

\section{Discusión}

En la actualidad, la internacionalización se ha consolidado como uno de los principales objetivos de cada actor involucrado en el quehacer científico y se ha permeado con especial fuerza en todos los procesos relacionados con la generación de conocimiento científico, desde su concepción hasta su comunicación. Si se ha legitimado como una característica tácita de la transferencia del conocimiento, el debate sobre la internacionalización debiera hacerse, entonces, en torno a los términos en que se busca llegar a esta y las consecuencias que trae consigo su búsqueda, en cada uno de los momentos que conforman el proceso de transferencia del conocimiento y en todos los actores. 


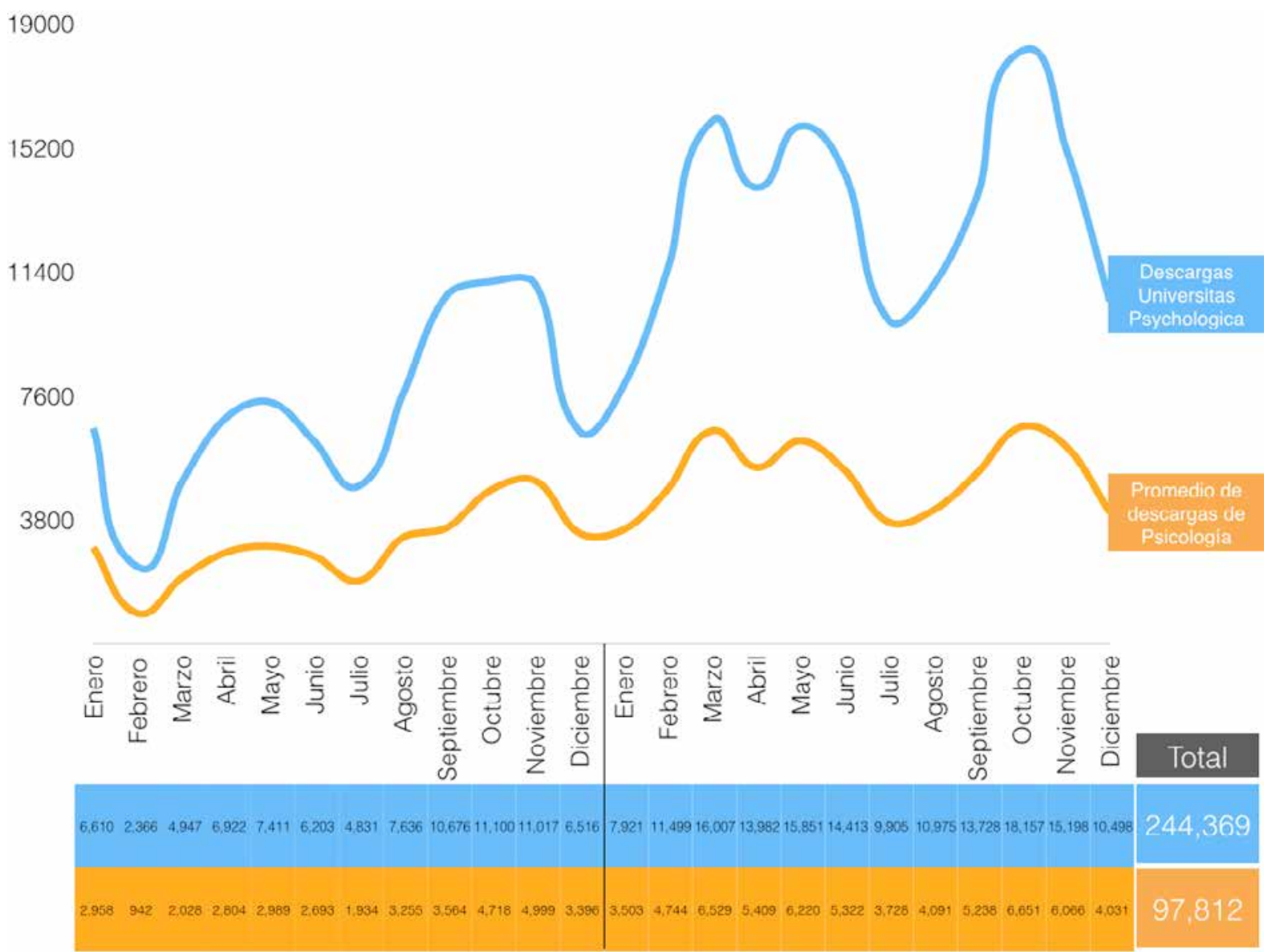

Figura 9. Descargas de Universitas Psychologica y promedio de descargas del área de psicología en redalyc.org, 2013 y 2014. Fuente: redalyc.org, UAEM.

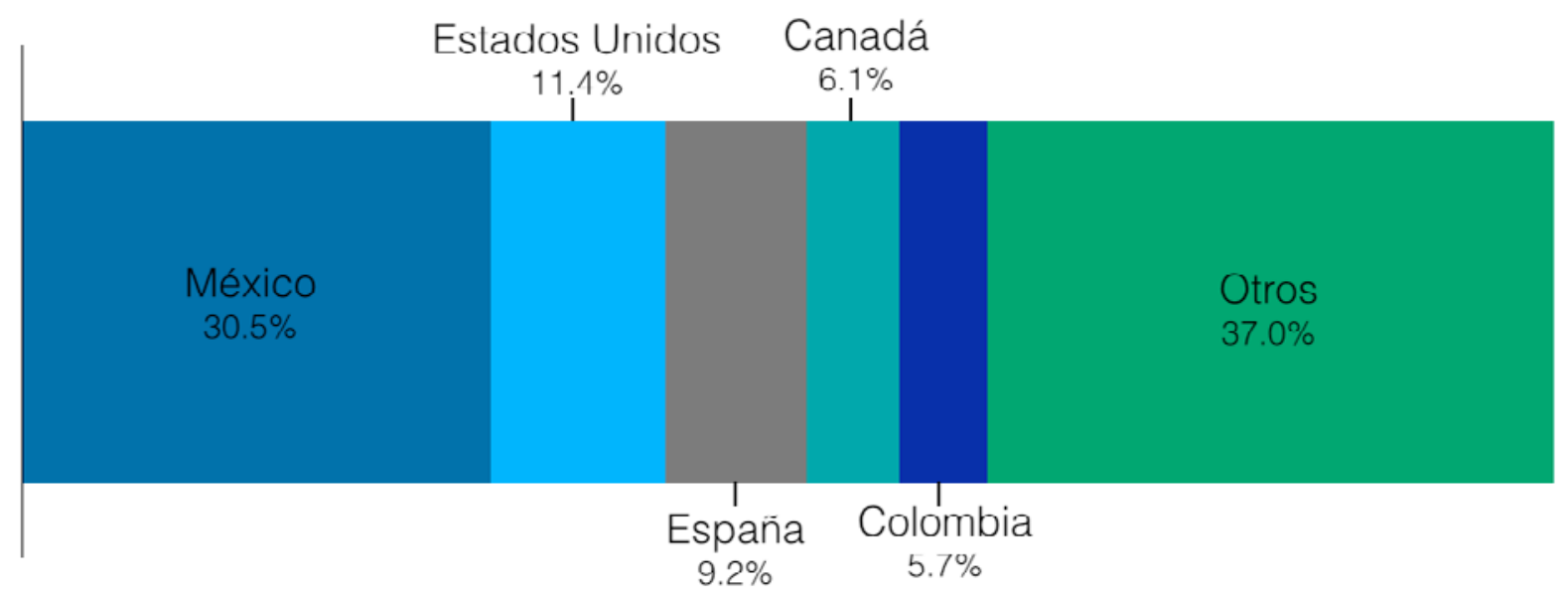

Figura 10. Principales países de descarga, Universitas Psychologica 2013 y 2014.

Fuente: redalyc.org, UAEM. 
Pensar, por ejemplo, que la concepción de los temas de investigación y la construcción de la agenda tienen que responder a estándares internacionales debiera asumir los riesgos que ello trae consigo. Ante la internacionalización de las agendas de investigación, cabe replantear su relevancia local y la producción, es decir, repensar la dirección cognitiva del quehacer científico, la generación de respuestas apropiadas a los contextos locales y hacer frente a las tensiones entre el conocimiento local y el internacional (Keim, 2010; Mouton, 2010; Vessuri, 2013b).

Un aspecto más por considerar es el relativo a la internacionalización de la evaluación del desempeño científico, traducido en los estándares que se sugieren a las diversas revistas para acceder a un índice o para buscar un alto factor de impacto. Trasladar el universalismo que se impuso en algún momento a la concepción de la ciencia (Olagüe de Ros, 2012) a la evaluación del quehacer científico podría llevar, en la práctica, en el caso de los proyectos editoriales, a una pérdida de identidad y una disolución de su hoja de ruta.

En términos de una mayor comunicación e integración al debate científico, la internacionalización de los actores y procesos involucrados al quehacer científico es una meta que debiera perseguirse. También sería relevante efectuar un ejercicio reflexivo de la pertinencia de las estrategias empleadas en este rubro.

En el ámbito de las revistas científicas, UP constituye un caso particular en el camino hacia la internacionalización; en la comunidad de psicología, se ha consolidado como un referente de visibilidad, dado que cuenta con la participación de actores internacionales en términos de autores, revisores, descargas y contenido (López-López, 2010, 2015; MarencoEscuderos, 2013). Esto sin duda ha implicado un esfuerzo editorial de comunicación y gestión importante. Cabe destacar el viraje que mostró a partir de 2007, año en que apostó por la internacionalización, adoptando entre sus estrategias la transformación a una publicación trimestral.

\section{Conclusiones}

UP tiene un papel de gran importancia en el camino hacia la internacionalización de la psicología, una construcción permanente en la cual, de entre todos los actores, destaca la labor de dicha revista en torno a la diversificación de sus contenidos y alcance, lo que se ha visto reflejado desde los indicadores de producción, colaboración y uso de redalyc.org, así como desde el Índice de Contribución y Esfuerzo Editorial propuesto.

Resalta que entre las 82 revistas de psicología de redalyc.org, la revista en cuestión ocupa la tercera posición por el porcentaje que representan los artículos donde participan autores extranjeros (92 \%), en 2014. La producción externa no solo representa la mayor parte del total de su producción, sino que muestra un ritmo de crecimiento de $39 \%$, notablemente superior al de la producción nacional (TCMA de $25 \%$ ) y que proyecta una tendencia que continuará al alza.

Por su parte, entre las variables que conforman la producción externa, pudo apreciarse que la colaboración entre extranjeros es la que está impulsando con mayor fuerza el ascenso de la producción externa, con 827 interacciones y 31 países; en segundo lugar, se tiene la participación de los extranjeros que han publicado individualmente, con 123 participaciones de 21 países; por último, está la colaboración entre autores extranjeros y autores adscritos a instituciones colombianas, con 113 interacciones de 14 países (además de Colombia).

Se observa un comportamiento no solo más exógeno, abierto a las fronteras nacionales, sino más diverso: mientras que en 2002 se tuvieron cinco participaciones de dos países, en 2014 se tuvieron 190 participaciones de 21 países y en 2015, 132 casos de 19 países. Esto representa un esfuerzo editorial por construir una revista plural, lo que además se refleja en que la participación de Colombia pasa de representar $67.9 \%$ en el periodo 2002-2006, a $21.5 \%$ en el 2007-2015.

La diversificación observada al exterior se aprecia también al interior del país editor y se constata en una mayor participación de autores adscritos a las múltiples instituciones colombianas: mientras la producción nacional no institucional presenta una TCMA de $52.2 \%$, la institucional registra $23 \%$, siendo que esta última, además, cayó de represen- 
tar el $100 \%$ al interior de la producción interna en 2002, a $33.3 \%$ en 2015.

Por su parte, el fomento hacia un esquema de trabajo inclusivo se aprecia también en términos de colaboración: los artículos en coautoría han tenido un ritmo de crecimiento superior al de las ciencias sociales y la psicología, en el acervo redalyc.org, además de tener una composición que se ha transformado y, de igual manera, diversificado: mientras que la producción en colaboración se compuso en 2002 por $80 \%$ de colaboración institucional y $20 \%$ de colaboración externa, en 2015 estuvo distribuida entre $51.8 \%$ de colaboración institucional, $22.9 \%$ de colaboración externa y 25.3 \% de colaboración nacional no institucional.

De igual forma, en términos de uso de la revista, se advierten tres hechos: el crecimiento de $58.8 \%$ de las descargas entre enero de 2013 y diciembre de 2014, un comportamiento de descargas que sobrepasa el promedio de las revistas de psicología de redalyc.org y un uso de la revista principalmente en el extranjero: $94.3 \%$ de las descargas se han realizado fuera de Colombia. Por último, sobresale su ICYEE, que pasa de 1.5 en 2002 a 4.7 en 2015, reflejo del esfuerzo editorial emprendido a lo largo de toda su trayectoria.

La ruta recorrida por UP debe continuar orientada por principios como la inclusión, diversificación y exogeneidad. Lo que en última instancia, además de derivar en la construcción de una revista internacionalmente consolidada, llevará sobre todo a fomentar un debate científico abierto y a cimentar una disciplina sólida.

\section{Referencias}

Aguado-López, E., \& Becerril-García, A. (2016). Revista Investigación Económica: análisis bibliométrico a partir de Redalyc.org, 2005-2014. Revista Investigación Económica, 77(295), 3-29. Recuperado de http://www.redalyc.org/pdf/601/60144179001.pdf

Banerjee, I., Babini, D., \& Aguado-López, E. (2015). Tesis a favor de la consolidación del Acceso Abierto como una alternativa de democratización de la ciencia en América Latina. En P. Suber, Acceso Abierto. Recuperado de http://ri.UAEM.mx/ handle/123456789/21710
Gallegos, M., Berra, M., Benito, E., \& López-López, W. (2014). Las nuevas dinámicas del conocimiento científico y su impacto en la psicología latinoamericana. Psicoperspectivas, 13(3), 106-117. Recuperado de http://www.psicoperspectivas.cl doi:10.5027/PSICOPERSPECTIVAS-VOL13-ISSUE3-FULLTEXT-377

Garfield, E. (2006). The history and meaning of the Journal Impact Factor. The Journal of the American Medical Association, 295(1), 90-93. Recuperado de http://garfield.library.upenn.edu/papers/jamajif2006.pdf

Keim, W. (2010). The internationalization of social sciences: Distortions, dominations and prospects. En World Social Science Report. 2010. Knowledge divides (pp. 160-170) París: UNESCO Publishig. Recuperado de http://unesdoc.unesco.org/ images/0018/001883/188333e.pdf

Kreimer, P. (2011). Internacionalização e tensões da ciência latino-americana. Ciência e Cultura, 63(2), 56-59. Recuperado de http://cienciaecultura.bvs. br/scielo.php?script=sci_arttext\&pid=S0009. $67252011000200018 \& \ln g=$ en\& $n r m=$ iso

López-López, W. (2010). Internacionalización y visibilidad del conocimiento. Universitas Psychologica, 9(2), 311-314. Recuperado de http://www.redalyc. org/articulo.oa?id=64716832001

López, M. P. (2013). Capacidades y condiciones institucionales de internacionalización en los grupos de investigación. Ciencia, Docencia y Tecnología, 24(46), 69-93. Recuperado de http://www.redalyc. org/articulo.oa?id=14527692003

López-López, W. (2014). Iberoamerican psychology: Challenges to the visibility of regional knowledge. Universitas Psychologica, 13(2), 419-421. Recuperado de http://www.redalyc.org/articulo. oa?id $=64732221001$

López-López, W. (2015). Changes in scientific output in psychology in Iberoamerica in the last decade. Universitas Psychologica, 14(4). Recuperado de http:// recursostic.javeriana.edu.co/sitio/psychologica/ sccs/tabla.php?id $=887$

Marenco-Escuderos, A. (2013). Redes de cooperación científica entre autores e indicadores bibliométricos de una revista de psicología en Colombia (Universitas Psychologica) durante el período 2009-2012. 
Realitas, Revista de Ciencias Sociales, Humanas y Artes, 1, 25-31. Recuperado de http://www.unireformada.edu.co/images/PDF/Realitas/5_Revista_ Vol_1_No_1_articulo_4.pdf

Mouton, J. (2010). The state of social science in sub-Saharan Africa. En World Social Science Report, 2010. Knowledge divides (pp. 63-67). París: UNESCO Publishig. Recuperado de http://unesdoc.unesco. org/images/0018/001883/188333e.pdf

Olagüe de Ros, G. (2012). Las relaciones del internacionalismo científico con los orígenes del movimiento documental europeo contemporáneo (1890-1945). Anales de Documentación, 15(2). http://dx.doi. org/10.6018/analesdoc.15.2.126421

Sá-Carvalho, M., Travassos, C., \& Medina-Coeli, C. (2014). La internacionalización de la ciencia (Editorial). Cadernos de Saúde Pública, 30(8). http:// dx.doi.org/10.1590/0102-311XED010814

Sánchez-Pereyra, A., Carrillo-Romero, O., \& GarridoVillegas, P. (2015). Análisis bibliométrico de la Revista Mexicana de Sociología basado en indicadores de citación. Revista Mexicana de Sociología, 77, 45-70. Recuperado de http://www.redalyc.org/ articulo.oa?id=32141043005

Santin, D. M., De Souza-Vanz, S. A., \& Caregnatom, S. E. (octubre, 2015). Internacionalidade das referências e citaçoes na produçao cientofica brasileira em biología evolutiva: 2000-2012. Presentado en XVI
Encontro Nacional de Pesquisa em Ciência da Informação, Paraíba, João Pessoa/PB. Recuperado de http://www.ufpb.br/evento/lti/ocs/index.php/enancib2015/enancib2015/schedConf/presentations

United Nations Educational and Cultural Organization [UNESCO](2010). Uneven internationalization. Chapter presentation. En World Social Science Report, 2010. Knowledge divides (pp. 141-164). París: UNESCO Publishig. Recuperado de http://unesdoc.unesco.org/images/0018/001883/188333e.pdf Vessuri, H. (2013a). ¿Quién es el científico social en el siglo XXI? Comentarios desde los contextos académicos y aplicados y desde la corriente principal y la periferia. Sociológica, 28(79), 201231. Recuperado de http://www.redalyc.org/ pdf/3050/305028347006.pdf

Vessuri, H. (2013b). El nuevo mantra de la diplomacia científica internacional: ico-diseño de conocimiento? ¿Investigación integrativa? Universitas Humanística, 76, 25-50. Recuperado de http:// revistas.javeriana.edu.co/index.php/univhumanistica/article/view/5905

Zych, I., \& Buela-Casal, G. (2007). Índice de internacionalidad de las revistas iberoamericanas de psicología incluidas en la web of science. Revista Mexicana de Psicología, 24(1), 15-22. Recuperado de http://www.redalyc.org/articulo. oa?id=243020635003 
